\title{
Stocking density and its influence on the productivity of red cusk eel, Genypterus chilensis (Guichenot, 1848), in shallow raceways
}

\author{
Atle Foss $^{1}$, Albert K.D. Imsland ${ }^{2,3}$, Felipe A. Briceño ${ }^{4}$, Spartaco Magnolfi ${ }^{5}$ \\ Piero Magnolfi ${ }^{5}$ \& Xavier Gutiérrez \\ ${ }^{1}$ Akvaplan-Niva, Bergen Office, Bergen, Norway \\ ${ }^{2}$ Akvaplan-Niva, Iceland Office, Kópavogi, Iceland \\ ${ }^{3}$ Department of Biological Sciences, University of Bergen, High Technology Centre \\ Bergen, Norway \\ ${ }^{4}$ Norwegian Institute for Water Research (NIVA) Chile S.A., Puerto Varas, Chile \\ ${ }^{5}$ Colorado Chile S.A., El Panul, Coquimbo, Chile \\ Corresponding author: Xavier Gutiérrez (xavier.gutierrez@nivachile.cl)
}

\begin{abstract}
We compared the growth properties of red cusk eel Genypterus chilensis with initial mean weight \pm standard error, $106.2 \pm 6.1 \mathrm{~g}$ reared in shallow raceways at three different stocking densities $(28.5,46.1$, and $60.7 \mathrm{~kg} \mathrm{~m}^{-3}$ ) in a 226-day long growth trial at a constant temperature of $17^{\circ} \mathrm{C}$. There was a trend towards higher specific growth rates at the highest density. Final mean weights were $333 \pm 12,352 \pm 12$, and $354 \pm 15 \mathrm{~g}$, at the 30,45 , and $60 \mathrm{~kg} \mathrm{~m}^{-3}$ density, respectively. Overall, the growth rates were higher in the $60 \mathrm{~kg} \mathrm{~m}^{-3}$ density group than the two other density groups. The daily feeding intake $(\%)$ was higher in the medium $(0.51)$, and high $(0.55)$ density groups compared the low-density group (0.45). Feed conversion efficiency (FCE) did not differ between the density groups. A significant size rank correlation was maintained in all density groups throughout the study. Calculated productivity increased almost linearly with increasing stocking density and was found to be 32,34 , and $39 \mathrm{~g} \mathrm{~m}^{-2} \mathrm{~d}^{-1}$ at 30,45 , and $60 \mathrm{~kg} \mathrm{~m}^{-3}$, respectively. The results show that the optimum density conditions for farming juvenile red cusk eel, both concerning growth rate, feed conversion, and productivity is at densities equal to or higher than $60 \mathrm{~kg} \mathrm{~m}^{-3}$.
\end{abstract}

Keywords: Genypterus chilensis; red cusk eel; stocking density; growth; shallow raceways; aquaculture

\section{INTRODUCTION}

The red cusk eel Genypterus chilensis (Guichenot, 1848 ) is a marine fish from the Ophidiidae family. Its geographical distribution extends from Paita in Peru to Cape Horn in southern Chile (Kong et al., 1988; Vega et al., 2018). It mainly inhabits coastal bodies of water at depths that generally range between 20 to $150 \mathrm{~m}$; it is a benthic species of the continental shelf usually found on rocky substrates, feeding on fish, crustaceans, and mollusks (Chong et al., 2006; Vega et al., 2018). G. chilensis has been a highly attractive resource for the local market due to the excellent quality of the meat, which has led to the overharvesting of this species over the last 12 years, producing a sharp decline in landing volumes (Chong et al., 2006; Vega et al., 2018). One alternative to solve the unmet demand of G. chilensis is its production through fish farming. Initial trials have focused on the development of incubation systems (Vega et al., 2012), juvenile growth under culture conditions (Vega et al., 2015), and reproduction of $G$. chilensis in captivity (Vega et al., 2018). Initial growth trials (Vega et al., 2015) in small quadrangular tanks (200 L) with three different size groups indicated that market size $(2 \mathrm{~kg})$ could be reached in 18-26 months from the initial size of 4 and $26 \mathrm{~g}$, respectively. No published growth trials exist for the red cusk eel in ongrowing systems.

The idea of using shallow raceway systems (SRS) for fish production appeared in the late eighties and has since been developed from an experimental scale into commercial large-scale production systems (e.g., Øiestad, 1999; Labatut \& Olivares, 2004; Imsland et al., 2009a). The technology is especially well suited for

Corresponding editor: Alejandra Volpedo 
land-based production of flatfish like turbot, Scophthalmus maximus (Rafinesque); Dover sole, Solea solea (Linaeus); Senegal sole, S. senegalensis (Kaup); and Atlantic halibut, Hippoglossus hippoglossus (Linaeus), or bottom-dwelling species like the spotted wolffish, Anarhichas minor (Olafsen), as it opens possibilities for a reduced land requirement and building investments as well as reduced water consumption, by stacking the raceways in several levels and re-using the water from level to level. The compactness and the system's self-cleaning properties, combined with high stocking density, are important characteristics of the shallow raceway system. Although the high density is considered a crucial property of the shallow raceway system, very little information exists on the effect of high density on the growth of candidate species reared in such a system.

Stocking density is a major factor affecting fish growth under farmed conditions (Kjartansson et al., 1988; Tremblay-Bourgeois et al., 2010; Calabrese et $a l ., 2017)$. Both negative and positive relationships between stocking density and growth have been reported, and the pattern of this interaction appears to be species-specific (Jørgensen et al., 1993; Björnsson, 1994; Irwin et al., 1999; Imsland et al., 2009a). However, no density studies have been performed and published for red cusk eel, and neither has the culture of the species in an SRS system been tried. Therefore, the following experiment was designed to investigate the effects of different rearing densities on the growth rate, size hierarchies, daily feed intake, feed efficiency ratio, and red cusk eel productivity in a shallow raceways system.

\section{MATERIALS AND METHODS}

\section{Fish stock and rearing conditions}

This experiment was undertaken between January and October 2018 at Colorado Chile S.A. facilities located

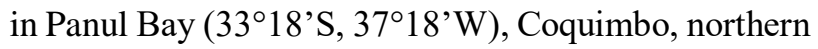
Chile. This study was conducted in a land-based recirculation aquaculture system facility designed for the red cusk eel Genypterus chilensis pre-rearing aquaculture stage. Red cusk eel juveniles were reared in shallow raceways and fed using a species-specific diet formulated by Cargill until the experiment. In December 2017, the fish were distributed randomly into six raceways $\left(0.45 \times 0.90 \mathrm{~m}, 0.40 \mathrm{~m}^{2}\right)$ with a water level of $26 \mathrm{~cm}$, each providing a total volume of 0.10 $\mathrm{m}^{3}$. The water flow was set to $20 \mathrm{~L} \mathrm{~min}^{-1}$ for each of the experimental units. In the shallow raceways, the water inlet pipe was in front of perforated screens. The inlet flow was pointed against the wall and away from the screens to avoid jet currents. Oxygen saturation was measured with a hand-held oxygen meter (OxyGuard Handy Polaris, OxyGuard International A/S, Denmark) at regular intervals in all raceways' effluent water. Adult red cusk eel prefers low light rearing conditions, and based on the experience gained by the fish farmer; it gets easily startled if much light is used. Accordingly, the fish were kept in the dark apart from during the period of daily feeding and cleaning routines.

\section{Experimental design}

The growth study was carried out from January 24, 2018 until October 17, 2018 with 255 red cusk eels. In each raceway, 20 fish were individually tagged using Trovan ${ }^{\circledR}$ Passive Transponder tags. Water was supplied from a recirculating aquaculture system (RAS) at a constant temperature of $17^{\circ} \mathrm{C}$, and oxygen levels were kept above $70 \%$ in the water outlet. Three experimental densities were applied: 28.5 (low), 46.1 (medium), and 60.7 (high) $\mathrm{kg} \mathrm{m}^{-3}$ with two replicate raceways for each experimental group. Hence, the experimental set-up is a two-way nested design, where the two replicates are nested within the experimental groups.

There are no published density studies on red cusk eel, but the North-Atlantic species spotted wolffish display many similar characteristics, including a similar body shape. In a density trial with spotted wolffish, Jonassen (2002) tested density in the range $20-60 \mathrm{~kg} \mathrm{~m}^{-2}$ for large juveniles and as no published trials existed on red cusk eel density, we used a similar range in this experiment.

All fish were anesthetized (benzocaine, $0.05 \mathrm{~g} \mathrm{~L}^{-1}$ ) and measured approximately monthly intervals throughout the experiment. Growth results are based on the tagged fish's registration, and other results are based on total biomass registrations.

The fish were fed twice a day using a speciesspecific diet formulated by Cargill. The first feeding was around 09:00 h, and the second feeding around 14:00 h. fish were fed until uneaten feed pellets were observed on the tank bottom when the feeding was haltered, to ensure satiation. Exact feeding registration was done in the first 60 days of the experiment, i.e., one for the first growth period (January-February) and the second one from February to March. There are two replicates for each experi-mental group and two measurement groups, i.e., $\mathrm{n}=4$, for each value in Table 1 .

\section{Feed data}

Total feed consumption $\left(\mathrm{C}_{\mathrm{T}}\right)$ was defined as the total feed supplied in each rearing unit daily. Daily feeding rate $(\mathrm{F} \%)$ was calculated as

$$
\mathrm{F} \%=100\left[\mathrm{C} /\left(\left(\mathrm{B}_{1}+\mathrm{B}_{2}\right) / 2\right)\right]\left(\mathrm{t}_{2}-\mathrm{t}_{1}\right)^{-1}
$$


Table 1. Average daily feeding rate (F) and feed conversion efficiency (FCE) of red cusk eel Genypterus chilensis reared at different densities in shallow raceways. Results are given as arithmetic mean \pm standard deviation for the two experimental periods where feeding data was sampled (i.e., $\mathrm{n}=4$ for each experimental group). Different superscript letters denote significant differences between the experimental groups (Student-Newman-Keuls multiple comparisons, $P<0.05)$.

\begin{tabular}{lcc}
\hline Experimental group & F\% & FCE \\
\hline Low density & $0.45 \pm 0.04^{\mathrm{b}}$ & $1.63 \pm 0.50$ \\
Medium density & $0.51 \pm 0.03^{\mathrm{a}}$ & $1.37 \pm 0.31$ \\
High density & $0.55 \pm 0.02^{\mathrm{a}}$ & $1.38 \pm 0.59$ \\
\hline
\end{tabular}

where $\mathrm{C}$ is feed consumption ( $\mathrm{g}$ dry matter) in the period, and $\mathrm{B}_{1}$ and $\mathrm{B}_{2}$ are fish biomass ( $\mathrm{g}$ wet weight) on days $t_{1}$ (start) and $t_{2}$ (final), respectively. Feed conversion efficiency (FCE) was calculated as biomass gain per weight unit of consumed feed:

$$
\mathrm{FCE}=\left(\mathrm{B}_{2}-\mathrm{B}_{1}\right) / \mathrm{C}
$$

\section{Data analysis and statistical methods}

Specific growth rate (SGR) was calculated according to the formula:

$$
\mathrm{SGR}=\left(\mathrm{e}^{g}-1\right) \times 100
$$

where $g=\left(\mathrm{LnW}_{2}-\mathrm{LnW}_{1}\right)\left(\mathrm{t}_{2}-\mathrm{t}_{1}\right)^{-1}$ and $\mathrm{W}_{2}$ and $\mathrm{W}_{1}$ are wet weights $(\mathrm{g})$ at days $\mathrm{t}_{2}$ and $\mathrm{t}_{1}$, respectively.

Productivity expressed as the amount of red cusk eel produced per $\mathrm{m}^{2}$ was calculated using the formula of Schram et al. (2006):

$$
P=\frac{\left(W_{\mathrm{f}}-W_{0}\right)}{A \times T}
$$

where P: productivity $\left(\mathrm{g} \mathrm{m}^{-2} \mathrm{~d}^{-1}\right) ; \mathrm{W}_{\mathrm{f}}$ : final biomass; $\mathrm{W}_{0}$ : initial biomass; $\mathrm{A}$ : mean rearing area $\left(\mathrm{m}^{2}\right)$; $\mathrm{T}$ : number of days.

A two-way nested ANOVA (Searle et al., 1992), where the two replicates were nested within density treatment, was applied to calculate the effect of different rearing density on mean weights and specific growth rates. The model equation of the nested ANOVA had the form:

$$
\mathrm{X}_{i j k}=\mu+\alpha_{i}+\mathrm{B}_{i j}+\varepsilon_{i j k}
$$

where $\mu$ is the general level; $\alpha_{i}$ is the treatment effect (i.e., density); $\mathrm{B}_{i j}$ is the contribution caused by replicate (here: raceways a and b) $j$ in group $i$ and $\varepsilon_{i j k}$ the error term. Significant ANOVAs were followed by a Student-Newman-Keuls multiple comparison test (Zar, 1984) to locate differences among treatments. For parameters where only group data existed (FCE, and F\%), a two-way nested ANOVA was applied, followed by a Student-Newman-Keuls multiple comparison tests to locate any differences among treatments.

Individual growth trajectories (IGT) were analyzed using a growth curve analysis (GCM) multivariate analysis of variance (MANOVA) model (Timm, 1980; Chambers \& Miller, 1995). The model equation of the GCM had the form:

$\mathbf{Y}_{(\mathrm{n} \times \mathrm{p})}=\mathbf{X}_{(\mathrm{n} \times \mathrm{q})} \mathbf{B}_{(\mathrm{q} \times \mathrm{p})}+\mathbf{E}_{(\mathrm{n} \times \mathrm{p})}$

where $\mathbf{Y}_{(\mathrm{n} \times \mathrm{p})}$ are the growth vectors

$\mathbf{y}=\left(\mathrm{y}_{1}, \mathrm{y}_{2}, \ldots, \mathrm{y}_{p}\right)$

for each $\mathrm{p}$ separate measurements on $\mathrm{n}$ individual fish; $\mathbf{X}_{(\mathrm{n} \times \mathrm{q})}$ is the design matrix or the set of variables measured for each individual, i.e., $q=\operatorname{age}_{p}+$ density $_{i}$ + replicate $_{j} ;\left(i=30,45\right.$ or $\left.60 \mathrm{~kg} \mathrm{~m}^{-3}\right),(j=$ replicate a, replicate $\left.b) ; \mathbf{B}_{(\mathrm{q}} \times \mathrm{p}\right)$ is the matrix of parameters estimated by the model; $\mathbf{E}_{(\mathrm{n} \times \mathrm{p})}$ is the matrix of deviations for each individual from the expected value of $\mathbf{Y}=\mathbf{X B}$.

Size ranking (initial size rank $v s$. final size rank) and growth rate ranking (initial SGR vs. final SGR and SGR's in adjacent periods) was tested using Spearman's rank correlation $\left(r_{S p}\right)$ (Zar, 1984). A Chi-squared test (Zar, 1984) was used for possible differences in the mortality of the tagged fish.

All statistical analyses were conducted using Statistica $^{\text {TM }} 13.3$ software. A significance level $(\alpha)$ of 0.05 was used in all statistical tests if not stated otherwise.

\section{RESULTS}

\section{Mortality}

During the experiment, five fish $(4.2 \%)$ died in the three density groups $(1,2$, and 2 tagged fish in low-, medium- and high-density groups, respectively), and the mortality did not vary between the experimental groups $\left(\chi_{1}^{2}<2.6, P>0.10\right)$.

\section{Growth: effect of density}

The initial mean weight \pm standard deviation (SD) was $106.1 \pm 3.7 \mathrm{~g}$ and did not differ significantly between the three densities (two-way nested ANOVA, $\mathrm{F}_{2,112}=$ $4.5, P>0.15$, Power $(1-\beta>0.3$, Fig. 1$)$. Final mean weights were $354.2 \pm 15.2,352.1 \pm 12.5$ and 333.1 $\pm 12.6 \mathrm{~g}$ for the high, medium and low-density groups, respectively. Specific growth rate (SGR) varied between the three density groups (two-way nested ANOVA, $P<0.05$, Fig. 2), and the high-density group had the highest growth initially and during March-April (SGR4) and July-August (SGR8). Overall growth was also highest in the high-density group (SNK post-hoc test, $P<0.05)$. 


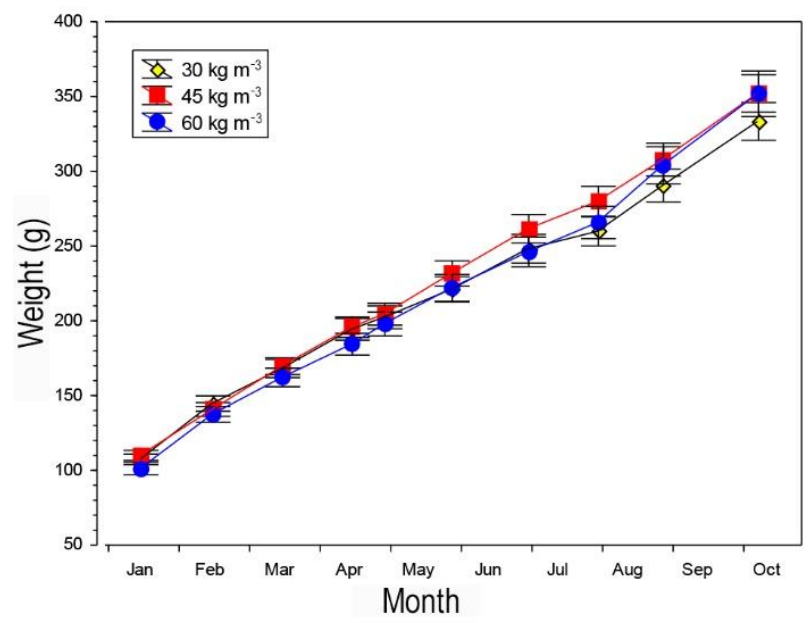

Figure 1. The mean weight of red cusk eel Genypterus chilensis reared in at different densities in shallow raceways. The vertical line indicating standard error may be obscured by symbol. The values for the two replicates are combined. $\mathrm{n}=37-40$ for each mean value. Diamond: $30 \mathrm{~kg} \mathrm{~m}^{-3}$, square: $45 \mathrm{~kg} \mathrm{~m}^{-3}$, circle: $60 \mathrm{~kg} \mathrm{~m}^{-3}$.

Overall, the mean individual growth trajectories (IGT) differed between the density groups, indicating that longitudinal growth profiles of the density group

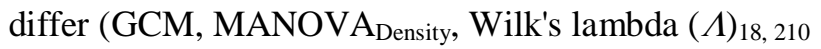
$=0.36, P<0.01)$, and the IGT were non-parallel between the groups, indicating differences in the groups

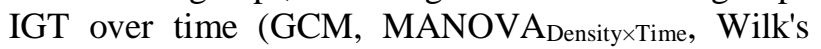
lambda $\left.(\Lambda)_{16,212}=0.38, P<0.01\right)$.

\section{Feed Intake and feed conversion efficiency}

Average feed conversion efficiency did not differ among density groups (Table 1). However, average feed intake differed between the density groups and was higher in the 45 (medium) (0.51) and 60 (high) $(0.55) \mathrm{kg} \mathrm{m}^{-3}$ groups (two-way nested ANOVA, $F_{2,6}=$ $8.5, P<0.05$, Table 1), compared to the $30 \mathrm{~kg} \mathrm{~m}^{-3}$ (low) density group $(0.45)$.

\section{Size and growth ranking}

A significant size rank correlation (initial weight $v s$. final weight) indicating stable size hierarchies was in all density groups $\left(r_{S p}>0.69, P<0.05\right)$, and was highest in the high-density group $\left(r_{S p}=0.79\right)$. Positive correlations between initial and final growth rates were not found in any density group $\left(r_{S p}<0.19, P>0.20\right)$. However, correlations between growth rates in adjacent periods (i.e., period $_{n}$ and period ${ }_{n+1}$ ) were only found once in the medium-density groups $\left(r_{S p}=0.32, P<\right.$ 0.05 , Table 2 ) and not seen in the high-density group, whereas this was seen in four out of eight growth periods in the low-density group $\left(r_{S p}>0.32, P<0.05\right.$, Table 2).

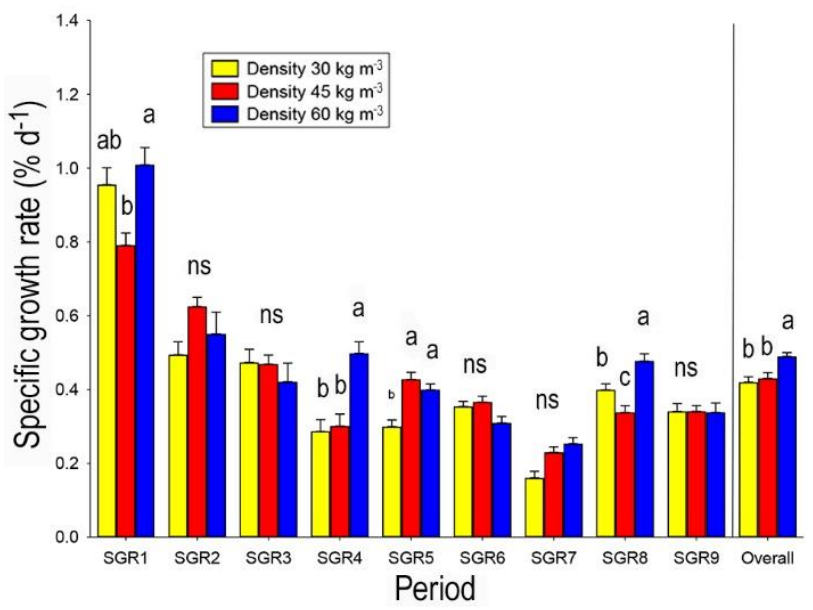

Figure 2. Specific growth rates of red cusk eel Genypterus chilensis reared in at different densities in shallow raceways. The vertical line indicates standard error. Different letters indicate statistical differences (two-way nested ANOVA, $P<0.05$ ), with 'a' as the highest value, 'b' as the second highest, and ' $c$ ' as the lowest value, ns not significant. The values for the two replicates are combined. $\mathrm{n}=37-40$ for each mean value.

\section{Productivity}

The relation between productivity as achieved in this experiment and stocking density is shown (Fig. 3). Productivity increased almost linearly with increasing stocking density and was calculated as 120,129 , and $146 \mathrm{~g} \mathrm{~m}^{-2} \mathrm{~d}^{-1}$ at low, medium, and high density respectively.

\section{DISCUSSION}

Stocking density is a crucial element in the rearing of demersal species like red cusk eel Genypterus chilensis and, there is a lack of systematic investigation on the subject for this species as previous studies have focused on the development of incubation systems (Vega et al., 2012) and reproduction of red cusk eel in captivity (Vega et al., 2018). The only previously published growth trial (Vega et al., 2015) on red cusk eel investigated growth in small quadrangular tanks (200 L) with three different size groups indicated that market size $(2 \mathrm{~kg}$ ) could be reached in 18-26 months from the initial size of 4 and $26 \mathrm{~g}$, respectively. Information about density-dependent growth in other demersal species is available, albeit not conclusive. In general, the available data on demersal fish are data from short term density trials with juveniles (turbot, Scophthalmus maxima, Irwin et al. (1999); winter flounder, Pseudopleuronectes americanus, Fairchild \& Howell (2001); spotted wolffish, Anarhichas minor, Jonassen (2002); Dover sole, Solea solea, Schram et al. (2006); California halibut, Paralichthys californicus, Merino et al. (2007), whereas data for larger fish are scarce (however 
Table 2. Correlations between specific growth rates (SGR) in adjacent periods (i.e., period ${ }_{n}$ and period ${ }_{n+i}$ ) of red cusk eel Genypterus chilensis reared at different densities in shallow raceways. Results are shown as Spearman's rank correlation $\left(r_{S p}\right)$ for each adjacent period along, number (n) of valid measurements in each group, and $P$-value. *Significant values $(P$ $<0.05)$.

\begin{tabular}{lcccc}
\hline Pair of variables & Experimental group & $\mathrm{n}$ & Spearman's rank correlation & $P$-value \\
\hline SGR1 \& SGR2 & Low density & 39 & -0.084 & 0.611 \\
SGR2 \& SGR3 & Low density & 39 & 0.412 & $<0.010^{*}$ \\
SGR3 \& SGR4 & Low density & 39 & 0.412 & $<0.010^{*}$ \\
SGR4 \& SGR5 & Low density & 39 & 0.601 & $<0.001^{*}$ \\
SGR5 \& SGR6 & Low density & 39 & 0.250 & 0.123 \\
SGR6 \& SGR7 & Low density & 39 & 0.251 & 0.121 \\
SGR7 \& SGR8 & Low density & 39 & -0.069 & 0.674 \\
SGR8 \& SGR9 & Low density & 38 & 0.326 & $<0.050^{*}$ \\
\hline SGR1 \& SGR2 & Med. density & 40 & 0.319 & $<0.050^{*}$ \\
SGR2 \& SGR3 & Med. density & 40 & 0.253 & 0.114 \\
SGR3 \& SGR4 & Med. density & 40 & 0.071 & 0.661 \\
SGR4 \& SGR5 & Med. density & 40 & 0.016 & 0.918 \\
SGR5 \& SGR6 & Med. density & 40 & 0.231 & 0.151 \\
SGR6 \& SGR7 & Med. density & 40 & 0.113 & 0.484 \\
SGR7 \& SGR8 & Med. density & 40 & 0.228 & 0.156 \\
SGR8 \& SGR9 & Med. density & 38 & 0.307 & 0.056 \\
\hline SGR1 \& SGR2 & High density & 39 & 0.092 & 0.573 \\
SGR2 \& SGR3 & High density & 39 & 0.114 & 0.486 \\
SGR3 \& SGR4 & High density & 39 & 0.231 & 0.260 \\
SGR4 \& SGR5 & High density & 39 & -0.089 & 0.589 \\
SGR5 \& SGR6 & High density & 39 & 0.171 & 0.197 \\
SGR6 \& SGR7 & High density & 39 & 0.207 & 0.205 \\
SGR7 \& SGR8 & High density & 39 & 0.198 & 0.225 \\
SGR8 \& SGR9 & High density & 37 & 0.302 & 0.065 \\
\hline
\end{tabular}

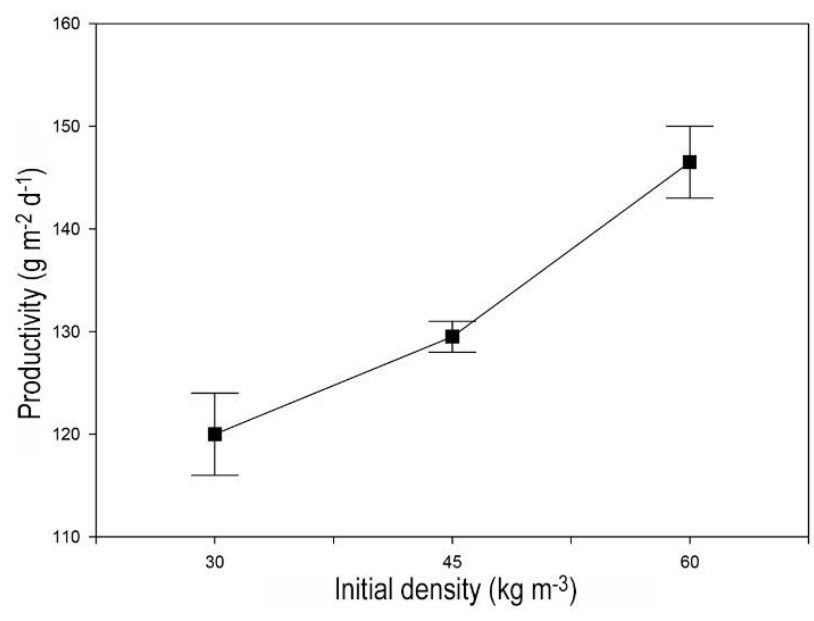

Figure 3. The relation between stocking density and productivity in red cusk eel Genypterus chilensis.

see data on large spotted wolffish (Imsland et al., 2009a). Irwin et al. (1999) reported the best growth for turbot juveniles (between 8-40 g) at medium $\left(6 \mathrm{~kg} \mathrm{~m}^{-2}\right)$ and high $\left(7 \mathrm{~kg} \mathrm{~m}^{-2}\right)$ densities. No effect of stocking density on growth was found for juvenile (0.2-2 g) winter flounder up to $350 \%\left(3 \mathrm{~kg} \mathrm{~m}^{-2}\right)$ bottom coverage (Fairchild \& Howell, 2001). Schram et al. (2006) reared juvenile $(20-50 \mathrm{~g})$ Dover sole at densities between 0.6 and $12.6 \mathrm{~kg} \mathrm{~m}^{-2}$ and found that Dover's growth rate significantly decreased with increasing stocking density.

For larger fish, Björnsson (1994) reported the optimal density of Atlantic halibut Hippoglossus hippoglossus to be between $20-40 \mathrm{~kg} \mathrm{~m}^{-2}$ for $1 \mathrm{~kg}$ fish and between $25-55 \mathrm{~kg} \mathrm{~m}^{-2}$ for $2 \mathrm{~kg}$ fish. Martínez-Tapia \& Fernández-Pato (1991) reared turbot (6-1000 g) at two densities and reported higher growth for turbot reared at a final density of $68 \mathrm{~kg} \mathrm{~m}^{-2}$ (initial density of $0.5 \mathrm{~kg} \mathrm{~m}^{-2}$ ) compared to a final density of $17 \mathrm{~kg} \mathrm{~m}^{-2}$ (initial density of $0.25 \mathrm{~kg} \mathrm{~m}^{-2}$ ). Imsland et al. (2009a) studied the growth of spotted wolffish with initial mean weight $3.65 \pm 0.15 \mathrm{~kg}$ reared in shallow raceways at three different densities $\left(50,70\right.$, and $90 \mathrm{~kg} \mathrm{~m}^{-2}$, corresponding to approx. 170,240 and $310 \mathrm{~kg} \mathrm{~m}^{-3}$, respectively) in a 447-day long growth trial. They found that there was a trend towards higher specific growth rates at the highest density. All these studies indicate that growth may be equally good or better at 
medium and high densities than low densities, which is in line with current findings on juvenile red cusk eel.

There are no published density studies on red cusk eel. However, the northAtlantic species spotted wolffish display many similar characteristics, including similar body shape and low light preference. Some published density trials from that species can give some insight into the effect of different density on growth in these bottom-dwelling species (e.g., spotted wolffish, Jonassen, 2002; Imsland et al., 2009a ; TremblayBourgeois et al., 2010). Jonassen (2002) and TremblayBourgeois et al. (2010) both found a negative effect of high density on growth, whereas we found the opposite result in the present study. A reduced feed intake explained the negative impact of stocking density found by Jonassen (2002) and Tremblay-Bourgeois et al. (2010) in the high-density group, which might cause increased social interactions between individuals (Irwin et al., 1999; Lambert \& Dutil, 2001). In the study of Imsland et al. (2009a), feed intake was not reduced in the high-density groups. However, there was a tendency towards higher feed conversion efficiency at higher densities indicating that social interactions did not cause a higher degree of competition at high densities, similar to present findings where both growth and feed intake increased with higher density. Hence, the positive impact of high density on growth in red cusk eel seen in the present study may be at least partly explained by the increased feeding intake seen for this group. The present study was not exactly designed to examine feeding; this was extra information provided by the fish farmer (Colorado Chile S.A.). Future studies using similar, or higher, densities should also consider behavioral components that allow a better understanding of social interaction (e.g., size hierarchies), growth, and feeding.

Density is tightly linked with the formation of size hierarchies and social interactions (Imsland et al., 1998, 2009b; Kooijman, 2009). To enlighten whether and to which extent social interactions in turbot contribute to observed size variation in large rearing groups, Imsland et al. (1998) used a growth model simulation study and the size variation of the model data compared with the laboratory data of Sunde et al. (1998). Although difficult to measure directly in the form of size hierarchies, the results showed that social interactions do contribute to size variation in demersal fish culture (Imsland et al., 1998). Some studies indicate that intraspecific competition and agonistic interaction is, in fact, greater when fish of similar size are reared together (Doyle \& Talbot, 1986; Baardvik \& Jobling, 1990; Imsland et al., 1998). Imsland et al. (2009a,b) pointed out that this has two important consequences: a) a certain level of size variation is needed to reduce the adverse effects of social interactions, and

b) demersal fish must be reared at optimal density as too low density will reduce growth due to a higher social interaction level.

Correlation between adjacent growth rates was seen in this study but was much more pronounced in the lowdensity group. It could indicate that stringent social hierarchies may have formed in the low-density group, which may have negatively affected growth as growth can be suppressed by competition under such conditions (Imsland et al., 1998). Further, we found high size rank correlation observed at in all density groups in the present study that may indicate the establishment of stable size ranks (hierarchies), which is common under culture conditions (Huntingford et al., 1990; Imsland et al., 1998). It has been pointed out by Klokseth \& Øiestad (1999) and Øiestad (1999) that less antagonistic behavior can be expected in the shallow raceway system compared to other rearing systems. As feed is floating and passing all individuals in the system, there will be less competition. Such a mechanism was indicated by Imsland et al. (2007) as less stringent formations of hierarchies were found in shallow raceways than conventional tanks.

In general, only a minor difference in mean weights was seen in the present study. However, the present findings' actual value is presented in the productivity calculations, as there is an almost linear increment in productivity between low, medium, and high density (Fig. 3). It is necessary to operate with the highest possible stocking densities in each rearing unit without compromising the fish's water quality or welfare to maximize productivity. As with any farming system, the shallow raceways system (SRS) success depends on good water quality control facilitated by the onedirectional current (plug-flow) and the homogeneity of water quality at an SRS outlet. The high degree of water-reuse to be applied must be coupled with substantial monitoring and control of waste products. The volume of water that has to be monitored and treated is considerably less than conventional technology (about 20\%). Thus, easier to deal with previous trials with demersal fish species in SRS have not found any negative effect on growth, blood physiology, or water quality (Labatut \& Olivares, 2004; Imsland et al., 2007, 2009a), and the system is costeffective for production of turbot (Bjørndal \& Øiestad, 2010) and sole (Bjørndal et al., 2016). This maximum stocking density should not have negative consequences on growth (Björnsson, 1994; Lambert \& Dutil, 2001; Schram et al., 2006; Imsland et al., 2009a; present study) or the general welfare of the fish (e.g., 
disease susceptibility, Fairchild \& Howell, 2001; induction of stress response, Ruane et al., 2002; present study Xavier Gutiérrez, NIVA Chile, pers. comm.). As no such negative effects were apparent in the present study, it may be deduced that maximum productivity of juvenile red cusk eel is reached at densities similar to the high-density group initial density of $60 \mathrm{~kg} \mathrm{~m}^{-3}$ in the present study.

\section{ACKNOWLEDGMENTS}

The work was funded by CORFO Chile "Programa Tecnológico Estratégico (PTE-Congrio) en Congrio Colorado y Dorado: Portafolio de Proyectos de Investigación y Desarrollo Estratégico para Habilitar una Nueva Industria Acuicultura en Chile".

\section{REFERENCES}

Bjørndal, T. \& Øiestad, V. 2010. The development of a new farmed species: production technology and markets for turbot. Working paper 2010: 51. [http:// idtjeneste.nb.no/URN:NBN:no-bibsys_brage_24087]. Reviewed: November 18, 2019.

Bjørndal, T., Guillen, J. \& Imsland, A.K. 2016. The potential of aquaculture sole production in Europe: production costs and markets. Aquaculture Economics and Management, 20: 109-129.

Björnsson, B. 1994. Effects of stocking density on growth rate of halibut (Hippoglossus hippoglossus L.) reared in large circular tanks for three years. Aquaculture, 123: 259-270.

Baardvik, B.M. \& Jobling, M. 1990. Effect of size-sorting on biomass gain and individual growth rates in Arctic charr, Salvelinus alpinus L. Aquaculture, 90: 11-16.

Calabrese, S., Nilsen, T.O., Ebbesson, L., Pedrosa, C., Fivelstad, S., Hosfeld, C., et al. 2017. Stocking density limits for post-smolt Atlantic salmon (Salmo salar L.). Aquaculture, 468: 363-370.

Chambers, R.C. \& Miller, T.J. 1995. Evaluating fish growth by means of otolith increment analysis: special properties of individual-level longitudinal data. In: Secor, D.H., Dean, J.M. \& Campana, S.E. (Eds.). Recent developments in fish otolith research. University of South Carolina Press, South Carolina, pp. 155-175.

Chong, J., Sepúlveda, K. \& Ibáñez, M. 2006. Variación temporal en la dieta del congrio colorado, Genypterus chilensis (Guichenot, 1881) frente al litoral de Talcahuano, Chile (36 $\left.32^{\prime} \mathrm{S}, 36^{\circ} 45^{\prime} \mathrm{S}\right)$. Revista de Biología Marina y Oceanografía, 41: 195-202.

Doyle, R.W. \& Talbot, A.J. 1986. Artificial selection on growth and correlated selection on competitive behaviour in fish. Canadian Journal of Fisheries and Aquatic Sciences, 43: 1059-1064.

Fairchild, E.A. \& Howell, W.H. 2001. Optimal stocking density for juvenile winter flounder Pseudopleuronectes americanus. Journal of World Aquaculture Society, 32: 300-308.

Huntingford, F., Metcalfe, N.B., Thorpe, J.E., Graham, W.D. \& Adams, C.E. 1990. Social dominance and body size in Atlantic salmon parr, Salmo salar L. Journal of Fish Biology, 36: 877-881.

Imsland, A.K., Nilsen, T. \& Folkvord, A. 1998. Stochastic simulation of size-variation in turbot: possible causes analyzed with an individual-based model. Journal of Fish Biology, 53: 237-258.

Imsland, A.K., Jenssen, M.D., Jonassen, T.M. \& Stefansson, S.O. 2009b. Best among unequals? Effect of different size grading and social environments on the growth performance of juvenile Atlantic halibut. Aquaculture International, 17: 217-227.

Imsland, A.K., Gunnarsson, S., Foss, A., Sigurðsson, B. \& Sigurðsson, S. 2009a. Stocking density and its influence on growth of spotted wolffish, Anarhichas minor, in shallow raceways. Journal of World Aquaculture Society, 40: 762-770.

Imsland, A.K., Foss, A., Gunnarsson, S., Sparboe, L.O., Øiestad, V. \& Sigurðsson, S. 2007. Comparison of juvenile spotted wolffish Anarhichas minor growth in shallow raceways and circular tanks. Journal of World Aquaculture Society, 38: 154-160.

Irwin, S., O'Halloran, J.O. \& FitzGerald, R.D. 1999. Stocking density, growth and growth variation in juvenile turbot, Scophthalmus maximus (Rafinesque). Aquaculture, 178: 77-88.

Jonassen, T.M. 2002. Effects of photoperiod, stocking density, and diet on growth in young spotted wolffish (Anarhichas minor Olafsen). Aquaculture International, 10: 411-420.

Jørgensen, E.H., Christiansen, J.S. \& Jobling, M. 1993. Effects of stocking density on food intake, growth performance and oxygen consumption in Arctic charr (Salvelinus alpinus). Aquaculture, 110: 191-204.

Kjartansson, H., Fivelstad, S., Thomassen, J.M. \& Smith, M.J. 1988. Effects of different stocking densities on physiological parameters and growth of adult Atlantic salmon (Salmo salar L.) reared in circular tanks. Aquaculture, 73: 261-274.

Klokseth, V.H. \& Øiestad, V. 1999. Forced settlement of metamorphosing halibut (Hippoglossus hippoglossus L.) in shallow raceways: growth pattern, survival and behaviour. Aquaculture, 176: 117-133.

Kooijman, S.A.L.M. 2009. Social interactions can affect feeding behaviour of fish in tanks. Journal of Sea Research, 62: 175-178. 
Kong, I., Meléndez, R. \& Henríquez, G. 1988. Los peces ophidiformes de aguas profundas entre Arica (18 $16^{\circ} \mathrm{S}$ ) e isla Mocha (38³0’S). Estudios Oceanológicos, 7: 1-15.

Labatut, R.A. \& Olivares, J.F. 2004. Culture of turbot (Scophthalmus maximus) juveniles in shallow raceways tanks and recirculation. Aquacultural Engineering, 32: 113-127.

Lambert, Y. \& Dutil, J.D. 2001. Food intake and growth in adult cod (Gadus morhua L.) reared under different conditions of stocking density, feeding frequency and size-grading. Aquaculture, 192: 233-247.

Martínez-Tapia, C. \& Fernández-Pato, C.A. 1991. Influence of stock density on turbot (Scophthalmus maximus L.) growth. ICES Journal of Marine Science, CM 1991/F: 20.

Merino, G.E., Piedrahita, R.H. \& Conklin, D.E. 2007. The effect of fish stocking density on the growth of California halibut (Paralichthys californicus) juveniles. Aquaculture, 265: 176-186.

Ruane, N.M., Carballo, E.C. \& Komen, J. 2002. Increased stocking density influences the acute physiological stress response of common carp Cyprinus carpio (L.). Aquaculture Research, 33: 777-784.

Searle, S.R., Casella, G. \& McCulloch, C.E. 1992. Variance components. John Wiley \& Sons, New York.

Schram, E., Van der Heul, J.W., Kamstra, A. \& Verdegem, M.C.J. 2006. Stocking density-dependent growth of Dover sole (Solea solea). Aquaculture, 252: 339-347.

Sunde, L.M., Imsland, A.K., Folkvord, A. \& Stefansson, S.O. 1998. Effects of size grading on growth and survival of juvenile turbot reared at two temperatures. Aquaculture International, 6: 19-32.

Received: 17 March 2019; Accepted: 21 July 2020
Timm, N.H. 1980. Multivariate analysis of variance of repeated measurements. In: Krishnaiah, P.R. (Ed.). Handbook of statistics. Analysis of variance. NorthHolland Publishing, Amsterdam, pp. 41-87.

Tremblay-Bourgeois, S., Le François, N.R., Roy, R.L., Benfey, T.J. \& Imsland, A.K. 2010. Effect of rearing density on the growth and welfare indices of juvenile spotted wolffish, Anarhichas minor (Olafsen). Aquaculture Research, 41: 1179-1189.

Vega, R., Estrada, J.M., Ramírez, D., Flores, C., Zamorano, J., Encina, F., et al. 2015. Growth of cusk eel Genypterus chilensis juvenile in culture conditions. Latin American Journal of Aquatic Research, 43(2): 344-350.

Vega, R., Pradenas, M., Estrada, J.M., Ramírez, D., Valdebenito, I., Mardones, A., et al. 2012. Evaluación y comparación de dos sistemas de incubación de huevos de Genypterus chilensis (Guichenot, 1848). Latin American Journal of Aquatic Research, 40: 187200.

Vega, R., Sepúlveda, C., Barnert, M., Mardones, A., Encina-Montoya, F., Oberti, C., et al. 2018. Reproductive capacity of the red cusk-eel Genypterus chilensis (Guichenot, 1848) in captivity. Latin American Journal of Aquatic Research, 46: 489-494.

Øiestad, V. 1999. Shallow raceways as a compact, resource-maximizing farming procedure for marine fish species. Aquaculture Research, 20: 831-840.

Zar, J.H. 1984. Biostatistical analysis. Prentice-Hall, New Jersey. 